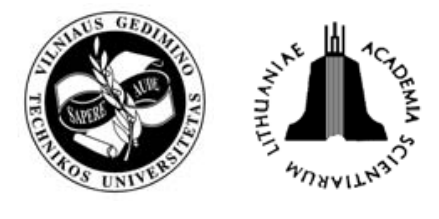

\title{
A SURVEY OF METHODS USED FOR ASSESSING THE PERFORMANCE OF DIESEL LOCOMOTIVES
}

\author{
Vidmantas Juršėnas, Gediminas Vaičiūnas \\ Dept of Railway Transport, Vilnius Gediminas Technical University, J. Basanavičiaus g. 28, \\ LT-03224 Vilnius, Lithuania.Phone: +370 5274 4803. E-mail: geltr@ti.vtu.lt
}

Received 1 September 2006; accepted 4 December 2006

\begin{abstract}
The present paper is aimed at evaluating the methods used for determining the performance of Diesel locomotives. Therefore, two main approaches to assessing the locomotive performance can be distinguished: a method based on individual indicators; a method based on an integrated indicator. The analysis of the available methods for complex evaluation of the locomotive condition has shown that overall performance of the locomotive can be described by a dimensionless indicator. In determining the state of Diesel locomotives, researchers rely on the criteria commonly used in assessing the performance of any machine. They are as follows: technical, economical, functional (operational).
\end{abstract}

Keywords: diesel locomotives, the performance of Diesel locomotives, complex evaluation of the locomotive condition.

\section{Introduction}

Diesel locomotives deteriorate with age. The need for schedule maintenance and materials increases, as well as the pollution of the environment. Different methods for assessing Diesel locomotive performance are currently used.

The present paper is aimed at evaluating the methods used for determining the performance of Diesel locomotives.

\section{Methods of evaluating Diesel locomotive performance}

Various criteria describing the state of a locomotive from various perspectives can be used to assess its performance. Some complex or integrated criteria reflecting a general state of Diesel locomotives can also be used. Therefore, two main approaches to assessing the locomotive performance can be distinguished:

1. a method based on individual indicators,

2. a method based on an integrated indicator.

In determining the state of Diesel locomotives, researchers rely on the criteria commonly used in assessing the performance of any machine. They are as follows:

1. technical,

2. economical,

3. functional (operational).

Technical criteria describe the parameters (values) of individual units or parts (which can break, stick or heavily wear).

Economical criteria (based on evaluation of maintenance costs) determine the increase of maintenance costs due to wearing, microcracks and residual deformations, as well as appropriateness of further use of particular locomotives.

Functional criteria reflect the variation of operational characteristics of Diesel locomotives at various stages of operation on which traffic and freight safety largely depends [1].

In recent years, the environmental criterion has considerably grown in importance. It is well-known that exhaust gases make the main source of air pollution. To generate an integrated performance indicator, individual indicators are grouped according to the above categories.

\section{Mathematical models used for assessing the performance of Diesel locomotives}

In this paper, two approaches are analysed. By the first method [2], an integrated performance indicator characterizing the locomotive performance is expressed by the following functional relationship:

$$
\gamma=f\left(\gamma_{1}, \gamma_{2}, \ldots, \gamma_{N-1}, \gamma_{N}\right)
$$

where $\gamma_{1,2, \ldots, N-1, N}$ is a particular indicator corresponding to the considered generalized criterion; $N=1,2,3 \ldots$

The particular criterion of Diesel locomotive performance is expressed by a functional relationship as follows:

$$
\gamma_{i}=f\left(n_{i 1}, n_{i 2}, \ldots, n_{i l-1}, n_{i l}\right)
$$

where $n_{11}, n_{12}, \ldots, n_{1 l-1}, n_{1 l}$ are relative indicators of the $l$-th parameter; $i=1,2,3 \ldots$ denotes the criterion index; $l=1,2,3 \ldots$ is an index of the parameter according to the respective criterion. 
By the first method [2] a relative indicator of the $l$-th parameter is determined by the formula:

$$
n_{k l}\left(\Delta t_{i}\right)=\frac{x_{k l}\left(\Delta t_{0}\right)}{x_{k l}\left(\Delta t_{i}\right)},
$$

where $x_{k l}$ is an actual value of the parameter, according to the $k$-th criterion; $k=1,2,3$ is the performance criterion index; $\Delta t_{0}$ is the initial observation interval; $\Delta t_{i}$ is a given observation interval; $i=1,2,3 \ldots$ is an index of observation interval.

One can see that the indicator described by the expression (3) shows worse locomotive performance according to the considered parameter since the parameter value is expected to grow over the time of the locomotive operation.

A mathematical expression of a particular indicator according to the technical criterion is as follows:

$$
\gamma_{1}=n_{11} \cdot n_{12} \cdot n_{13},
$$

where $n_{11}$ is a relative indicator of Diesel engine failures; $n_{12}$ is a relative indicator of electrical equipment failures; $n_{13}$ is a relative indicator of undercarriage failures.

According to the economical criterion, the following mathematical expression is obtained:

$$
\gamma_{2}=n_{21} \cdot n_{22} \cdot n_{23},
$$

where $n_{21}$ is a relative indicator of diesel oil consumption; $n_{22}$ is a relative indicator of engine oil consumption; $n_{23}$ is a relative indicator of unscheduled idle time.

According to the functional (operational) criterion, the following mathematical expression is obtained:

$$
\gamma_{3}=n_{31} \cdot n_{32} \cdot n_{33},
$$

where $n_{31}$ is a relative indicator of traction force; $n_{32}$ is a relative indicator of the locomotive speed; $n_{33}$ is a relative indicator of braking efficiency.

According to the above method, a relative indicator corresponding to the environmental criterion should be determined based on the amount of pollutants specified by the current environment protection regulation of the Republic of Lithuania LAND 18-2003/M-03. According to the environmental criterion, the following mathematical expression is obtained:

$$
\gamma_{4}=n_{41} \cdot n_{42} \cdot n_{43} \cdot n_{44},
$$

where $n_{41}$ is a relative indicator of nitrogen oxide emission; $n_{42}$ is a relative indicator of carbon monoxide emission; $n_{43}$ is a relative indicator of hydrocarbon emission; $n_{44}$ is a relative indicator of hard particles emission.

According to the method discussed, an integrated performance indicator is expressed mathematically as a product of all particular indicators:

$$
\gamma=\gamma_{1} \cdot \gamma_{2} \cdot \gamma_{3} \cdot \gamma_{4}
$$

The numerical value of the integrated indicator ranges from 0 to 1 . The initial value at the beginning of observation is equal to one (unity).

According to the second method [3], the integrated performance indicator of rolling stocks takes into account the costs of fuel, oil and off-schedule repairs. It is expressed in this way:

$$
K=d \cdot I_{d}+a \cdot I_{a}+p \cdot I_{p}
$$

where $K$ is the integrated performance indicator of rolling stocks, $\mathrm{Lt} / 10$ thous. tonne-km; $d$ is relative fuel consumption, $\mathrm{kg} / 10$ thous. tonne-km; $a$ is relative oil consumption, $\mathrm{kg} / 10$ thous. tonne-km; $p$ is the cost of off-schedule repairs, $\mathrm{h} / 10$ thous. tonne-km; $I_{d}$ is the cost of fuel, $\mathrm{Lt} / \mathrm{kg}$; $I_{a}$ is the cost of oil, $\mathrm{Lt} / \mathrm{kg} ; I_{p}$ is the cost of a relative repair unit, Lt/h.

In order to use the indicators of rolling stocks performance irrespective of the quantitative expression of the financial maintenance indicators, the performance indicators should be dimensionless values. The indicator in question is considered to be equal to one in its graph break point, i.e. the values of all equation terms are divided by a fixed number.

\section{Research results}

Twenty locomotives of various service life were investigated. According to the first two methods, the locomotives were combined into four groups based on their age, which was 11-15 years, 16-20 years, 21-25 years and $26-30$ years.

According to the first approach, $\gamma$ distribution shown in Fig 1 was obtained, when all relative indicators were given the values of 1.0 at the initial point of observation. It is shown that the performance of the locomotives of 26-30 years of age was reduced by 4,07 times compared to that of 16-20 year-old locomotives.

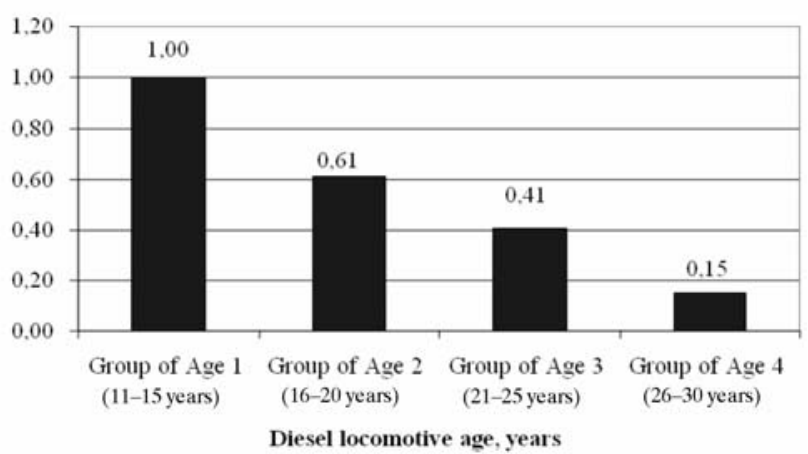

Fig 1. The relationship between the value of integrated performance indicator and the locomotive age (obtained by the first method of evaluation)

According to the second technique, a dimensionless performance indicator is obtained. Its value at the break point is assumed to be equal to 1.0. In Fig 2, the relationship between the dimensionless indicator and the locomotive age is presented. 
The relationship for 20-year old locomotives is shown in Fig 2:

$$
K_{2 M 62}=0.071 \cdot x^{2}-2.709 \cdot x+68,
$$

where $x$ is the locomotive age, in years.

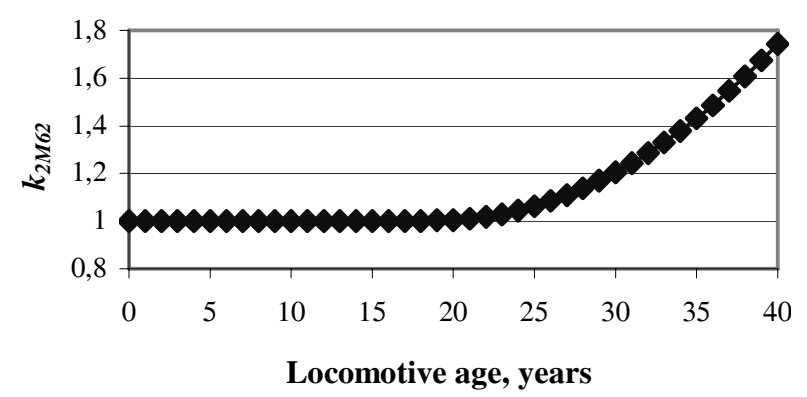

Fig 2. The relationship between the dimensionless indicator and the locomotive age

The data presented in Fig 2 also show that the locomotives 2M62 (2 sections) should be written off after 20 years of service life (because later the dimensionless indicator increases by 1.085 times per 5 years).

\section{Conclusions}

1. The analysis of the available methods for complex evaluation of the locomotive condition has shown that overall performance of the locomotive can be described by a dimensionless indicator.

2. When a locomotive with the specified service life of 20 years (which is the time of its complete wearing) has been used for 10 years, its performance has lowered by 4.07 times.

3. The locomotive performance hardly drops after 20 years of service life. It can be expressed by the 2 nd power polynomial equation.

\section{References}

1. LINGAITIS, L. P. Diagnostics of locomotives (Riedmenu diagnostika). Vilnius: Technika, 2000. 224 p. ISBN 998605-395-1 (in Lithuanian).

2. JURŠÉNAS, V. Technique of an estimation of complex quality of Diesel locomotives. In 6-th European Conference of Young Research and Science Workers in Transport and Telecommunications TRANSCOM 2005. Section 7: Machines and Equipment Applied mechanics. Proceedings. University of Žilina, Slovak Republic. Žilina: University of Žilina, 2005, p. 65-68. ISBN 80-8070-419-8.

3. VAIČIŪNAS, G.; LINGAITIS, L. P.; BUREIKA, G. The determination of a complex criterion for assessing the performance of traction rolling stocks. Transport, 2004, Vol XIX, No 2, p. 63-68. ISSN 1648-4142. 